\title{
Makina Öğrenmesi Yöntemleri ile Türk Mevduat Bankalarının Müşteri Tahminine Yönelik Bir Uygulama
}

Filiz YETIZ (https://orcid.org/0000-0001-5480-9268), AkdenizUniversity, Turkey; filizyetiz@akdeniz.edu.tr Mustafa TERZIOĞLU (https://orcid.org/0000-0002-4614-7185), Akdeniz University, Turkey; mterzioglu@akdeniz.edu.tr

Mehmet KAYAKUSS (https://orcid.org/0000-0003-0394-5862), Akdeniz University, Turkey; mehmetkayakus@akdeniz.edu.tr

\section{An Analysis of Turkish Deposit Banks' Customer Forecasting with Machine Learning Methods}

\begin{abstract}
Banks have expanded their marketing activities to uphold their existing customers and gain new customers to accentuate their market share in the sector. This study aims to emphasize the importance of customer forecasting and investigate the factors that are effective in determining the number of customer forecasting. Machine learning, artificial neural networks, and support vector machines methods are used. The variables commonly used in the literature, such as number of branches, number of employees, total deposits, total loans, were selected to determine customer estimates by considering the monthly data of deposit banks in the Turkish banking sector for the period 2011-2020. As a result of the analysis, the number of customers estimates of deposit banks in Turkey was successfully obtained. In light of these estimates, it is thought that banks can facilitate the creation of targets for identifying target customers they aim to provide services to in the future.
\end{abstract}

Keywords $\quad$ : Banking, Customer Relations, Customer Satisfaction, Customer Loyalty, Artificial Neural Networks, Support Vector Machines.

JEL Classification Codes : G20, G21, G29.

$$
\text { Öz }
$$

Bankalar, sektördeki pazar paylarını artırmak için pazarlama faaliyetlerini mevcut müşteriyi koruma ve yeni müşteri kazanma konusunda genişletmişlerdir. Çalışmanın amacı, müşteri sayısı tahmininin önemini vurgulamak ve müşteri sayısı tahmini belirlemede etkili olan etmenleri araştırmaktır. Çalışmada makine öğrenmesi yöntemlerinden yapay sinir ağları ve destek vektör makineleri kullanılmıştır. Çalışmada, Türk Bankacılık sektöründeki mevduat bankaların 2011-2020 dönemi aylık verileri kullanılarak şube sayısı, çalışan sayısı, toplam mevduat, toplam krediler gibi literatürde kullanılan değişkenler müşteri tahminini tespit etmede seçilmiştir. Analiz sonucunda, Türkiye'deki mevduat bankalarının müşteri sayısı tahminleri başarılı bir şekilde elde edilmiştir. Bu çalışmanın bankaların hizmet sunmayı hedeflediği hedef müşterileri belirleme aşamasında bankalara yol göstereceği düşünülmektedir.

\section{Anahtar Sözcükler $\quad$ : $\quad$ Bankacılık, Müşteri ilişkileri, Müşteri Memnuniyeti, Müşteri}

Sadakati, Yapay Sinir Ağları, Destek Vektör Makineleri. 
Yetiz, F. \& M. Terzioğlu \& M. Kayakuş (2021), "Makina Öğrenmesi Yöntemleri ile Türk Mevduat Bankalarının Müş̧eri Tahminine Yönelik Bir Uygulama”, Sosyoekonomi, 29(50), 413-432.

\section{Giriş}

Bankalar, hizmet sektörü içerisinde yer alan ve ekonomik büyümenin lokomotifini oluşturan önemli finansal kurumlardan biridir. Bankaların hizmet sunduğu müşteriler ise bankaların faaliyetlerine kârlı bir şekilde devam edebilmelerini sağlayan en değerli kaynağıdır. Bu bağlamda bankalar mevcut müşterileri ile çalışmalarına devam etmek ve yeni müşteriler kazanmak için farklı pazarlama stratejileri üzerinde çalışmaktadır. Bankalar açısından öncelik mevcut müşterilerin kendisine sunulan bankacılık hizmetinden memnun kalması böylece banka ile çalışmalarına devam etmesidir. Ayrıca bankalar mevcut müşterilerinin kullandıkları ürün yelpazesini genişleterek çalışmakta, müşterinin daha önceden kullanmadığı ürün ve hizmetlerin kullanması için ise azami çaba göstermektedir. Bankalar, mevcut müşterilerinin finansman ihtiyaçlarını zamanında belirlemek, finansman ihtiyaçlarına uygun kredi ve mevduat ürünlerini özel fiyatlamalarla kullandırmak, yeni ürün ve hizmetleri konusunda bilgi vermek ve müşterinin banka ile olan çalışmalarında devamlılığı sağlamak için her geçen gün yeni uygulamalar geliştirmektedir. Ancak hangi müşteriler ile çalışılacağ 1 , hangi müşteriler ile çalışmaların artırılacağ 1 ve hangi müşteriler ile çalışmaların azaltılacağı konusunda bankaların aktif ve pasif müşterilerine ait bilgilere ihtiyaç vardır. Bu çerçevede bankaların mevcut müşterilerini koruması hatta yeni müşterilere kolaylıkla ulaşabilmesi açısından çalışmaya devam edeceği müşteri bilgisine banka içi veya banka dışı kaynakları kullanarak hızlı bir şekilde ulaşması gerekmektedir.

Bankacılık sektöründe temel sorun müşteri sadakatini kaybetmemektir. Bu açıdan bankalar farklı yöntemler kullanmaktadır. En çok kullanılan yöntemler, tüm müşterilerine sürekli olarak belli zaman aralıklarıyla yeniliklerden ve kurum içerisinde gerçekleşen gelişmelerden haberdar tutmak için gerçekleştirilen müşteri ziyaretleridir. Müşteri ziyaretleri bankaların müşteri ilişkilerini yönettiği önemli bir pazarlama tekniğidir. Fakat bu iş ciddi bir çaba ve maliyet ortaya çıkarmaktadır. Bu maliyetin en aza indirilebilmesi için doğru müşteri kümesinin bulunması ve o yönde çaba sarf edilmesidir (Balcioglu \& Sezen, 2019).

Günümüz rekabet koşullarında bankalar, kârlılıklarını arttırmak ve devam ettirmek için yeni ürün ve yöntemleri pazarlamak için müşteri memnuniyetine özen göstermekte, müşterilerinin banka ile çalışmasını devam ettirmek için özen göstermektedirler. Bankalarda kobi kredilerinin değerlendirmesi (Yazıc1, 2007), kredi risk yönetimi tahmini (Pacelli \& Azzollini, 2011), mevduat bankalarının kârlılığının tahmini (Sönmez, Zontul \& Bülbül, 2015), bankacılık alanında müşteri kaybının öngörülmesi (Bilal-Zorić, 2016), banka müşterilerinin bankadan ayrılma olasılığının tahmini (Balcioglu \& Sezen, 2019) gibi bankacılık konularında literatürde yapay sinir ağları yöntemi kullanılmıştır. Literatürdeki bankacılık konularından farklı olarak bu çalışmada bankacılık sektöründe hizmet sunulan müşterinin önemli olduğu düşüncesi ile müşteri sayısının tahmini amaçlanmıştır. Ayrıca geleneksel yöntemlere göre (çoklu doğrusal regresyon vb.) gerçeğe yakın sonuçlar veren ve öngörü başarısı yüksek olan tahmin yöntemi olarak yapay sinir ağları ve destek vektör makinaları yöntemi kullanılmıştır. 
Ayrıca çalışmada banka müşteri sayısının tahmin edilmesi ile bankaların müşteri sadakati, müşteri memnuniyetini artırmak amaçlı gelecek politika hedeflerinin oluşturması konusunda destek olacağı düşünülmektedir. Bu çalışmayı literatürdeki diğer çalışmalardan farklılaştıran unsurlar ise, hem bankaların mevcut müşteri sayılarını düzenli takip edebilmeleri açısından bankalara önemli bilgiler vermesi hem de son zamanlarda bankacılık literatüründe kullanılan yapay sinir ağları ve destek vektör regresyonu yöntemlerinin kullanılmasıdır.

$\mathrm{Bu}$ amaçla çalışmada, Türk Bankacılık sektöründeki mevduat bankalarının 20112020 dönemi aylık verileri aralığında, banka şube sayısı, çalışan sayısı, mevduat, krediler değişkeni müşteri tahminini etkileyen etmenler olarak çıkış değişkenleri olarak seçilmiştir. Bankalarda müşteri tahmini analizinde kullanılan değişkenlerinden biri banka şube sayısı ile şubelerde çalışan personel sayısıdır. Bankaların yeni müşteri kazandığı, müşterileriyle iletişimi güçlendirerek onları kalıcı kıldığı kanal olması ve çoğu müşterinin ilk erişim noktası olarak şube bankacılığını hâlâ tercih ediliyor olması nedenleriyle şubelerin varlığı sektör açısından önemlidir. Bankalar, şube sayılarını arttırmayı ve şubelerde daha çok pazarlamaya yönelik hizmet vermeyi tercih etmektedir (Başar, Kabak \& Topçu, 2015: 3). Türk bankacılık sektöründeki Mart 2021 itibariyle mevduat bankalarındaki banka şube sayısı 9.858 adet, çalışan sayısı 180.889 kişiye ulaşmıştır (TBB, 2021). Şube sayısı ve çalışan sayısı bankalarda ihtiyaca uygun şekilde artırıldığı zaman müşteri memnuniyeti artmakta ve müşteri sadakati sağlanmaktadır Buna bağlı olarak mevcut müşterilerin bankacılık hizmetlerine daha hızlı cevap verilebilmekte dolayısıyla müşterilerin banka ile çalışmaları devamlılık göstermektedir. Analizde kullanılan değişkenlerden diğerleri ise kredi ve mevduat değişkenleridir. Johnston 1997 yılında yaptığı çalışmada müşteri sadakatinde ve potansiyel müşterilerin bankayı tercih etmesinde temel unsurların bankaların sunduğu en önemli iki ürün olan mevduat ve kredi olduğunu belirtmiştir. Mevduat ve kredi ürünlerinin çeşitliliği hizmet kalitesini ve müşteri memnuniyetini artırmaktadır. Bu nedenle müşteriler bankaları ile çalışmalarını uzun süre devam ettirmektedirler (Johnston, 1997). Bu amaçla söz konusu bağımsız değişkenler bankalar ile çalışması devam eden mevcut müşterilerin sağlıklı bir şekilde öngörülebilmesi açısından tercih edilmiş ve çalışmamızda yer verilmiştir.

Yapılan analiz sonucunda, Türkiye'deki mevduat bankalarının müşteri tahminleri başarılı bir şekilde elde edilmiş ve bu tahminler 1şı̆̆ında bankaların gelecekte hizmet sunmayı amaçladığı yeni müşterileri belirleme hedeflerinin oluşturması aşamasında bankalara kolaylık sağlayabileceği düşünülmektedir. Ayrıca müşteri tahmin sonuçları, bankaların aktif müşterileri ile çalışmaya devam edip etmemeleri konusunda ve bu müşterilere yönelik hangi tür yeni finansal ürün ve hizmetleri oluşturması gerektiği konusunda stratejiler oluşturmalarına yardımcı olabilecektir. Müşteri tahmini analizi sonuçları belirli dönemlerde bankalar tarafından tekrarlandığında söz konusu bankayla çalışma sayısı artan veya azalan müşterilerin sayısı takip edilebilecektir. Çalışmamızdaki müşteri sayısını doğru bir şekilde tahminleme bu açıdan da önem arz etmektedir. 
Çalışmada değişkenlerin seçimi ve zaman periyodunu kapsayan iki sınırlılık vardır. Birincisi, Türk Mevduat Bankacılık Sektörü değerlendirmesi için 2011-2020 aylık dönemi verileri kullanılmıştır. İkinci sınırlılık ise değişkenlerin seçimi ve ülke ile ilgilidir. Çalışmada kullanılan değişkenler Türkiye ile sınırlıdır ve araştırmada incelenen banka sayısı 26 adettir. Türk Bankacılık sektöründeki mevduat bankalarının müşteri tahminin ölçütü olarak; banka şube sayısı, çalışan sayısı, mevduat, krediler değişkeni müşteri tahminini etkileyen bankacılık sektörünün iç dinamikleri değişken olarak seçilmiştir.

Çalışmanın birinci bölümü olan giriş kısmında müşterinin değeri ile bankalar açısından önemi açılanmış, ikinci bölümde literatür incelemesine yer verilmiştir. Çalı̧̧manın üçüncü bölümünde analizde kullanılan veri seti ve yöntem hakkında detaylı bilgiler verilmiştir. Dördüncü bölümde araştırmanın analiz sonuçları ve bulgulara, son bölümde ise çalışmayla ilgili tartı̧̧ma ve genel değerlendirmeler ele alınmıştır.

\section{Kavramsal Çerçeve ve Literatür Özeti}

Müşteri kavramı, işletmelerin sunduğu mal ve hizmetleri satın alan tüketiciler şeklinde ifade edilebilir. Tüketiciler bir mal veya hizmeti aldıklarında o ürünün müşterisi olmaktadırlar (Altuğ \& Özhan, 2018).

Yeni müşteri kazanmanın maliyeti mevcut müşteri ile çalışmanın maliyetinden altı kat daha fazla olduğu öngörülmektedir (Demir \& Kırdar, 2007). Bu durum bankaları mevcut müssterilerinin bankacılık faaliyetleri memnuniyetlerini sürekli iyileştirmeye zorlamaktadır. Müşteri memnuniyetinin devamlılı̆̆ının sağlanması bankacılık sektörü açısından oldukça önemlidir. Çünkü bankayla çalışmasını sürdüren mevcut müşteri bankanın kârlılığını sağlamada ve bankacılık hedeflerine kolay ulaşılmasında temel faktördür (Özdemir, 2012).

Bankacılığın en önemli sermayesi bireylerin bankacılık kurumuna, banka çalışanlarına güvenmesidir. Bankalar mevcut müşterileriyle aktif çalışmaya devam etmek için farklı, yeni müşterileri kazanmak için ise daha farklı yöntemler denemektedir. Ayrıca bankalar mevcut müşterilerin kullandıkları ürün sayılarını arttırmaya çalışmakta, mevcut müşterilerin sunulan diğer hizmetleri de kullanmaları için çaba göstermektedir. Bu bağlamda mevcut müşterilerin sık sık ziyaret etmek, müşteri ihtiyaçlarını belirlemek, her yeni ürün ve hizmet hakkında bilgilendirme yapmak bankaların müşteri ilişkilerini yönetmek aşamasında kullandığı temel ilkelerdendir (Gürbüz, 2016).

Literatürde, bankanın aktif müşterilerinin tahminlenmesi konusu ile ilgili çalışmalardan ziyade daha çok müşteri memnuniyeti, müşteri sadakati kapsamındaki çalışmaların ağırlıklı olduğu söylenebilir.

Araslı vd. (2009) çalışmalarında banka müşterilerinin beklentilerinin yeterince karşılanmadığı, empati boyutunda büyük farklılıklar olduğunu ve güven boyutunun müşteri memnuniyetinde önemli bir etkiye sahip olduğu sonucuna ulaşmışlardır (Arasli, Katircioglu \& Mehtap-Smadi, 2005). 
Gençtürk vd. (2011) çalışmalarında bireysel bankacılıkta müşterilerin memnuniyetini etkileyen faktörleri incelemişlerdir. Çalışma sonucunda hizmet kalitesinin müşteri memnuniyeti için önemli bir faktör olduğu tespit edilmiştir (Gençtürk, Kalkan, \& Oktar 2011).

Bülbül (2017) araştırmasına Türk bankacılık sektöründe faaliyet gösteren katılım bankalarını mevduat bankaları ile karşılaştırmıştır. Hizmet çeşitliliğii, faizle daha fazla kazanç sağlama olanaklarından ve mevduat bankalarının, katılım bankalarına kıyasla müşteri memnuniyeti açısından daha ileride olduğunu ortaya koymuştur (Bülbül, 2019).

Aydın ve Tavukçu (2019), Türkiye Katılım Bankacıllğı sektöründeki müşteri memnuniyeti, müşteri sadakati ve müşteri tavsiye etme üzerine bir inceleme yapmışlardır. İletişim, güven, yetkinlik ve çatışma yönetimlerinin, müşteri memnuniyeti, müşteri sadakati ve müşterilerin tavsiye etme eğilimine olumlu katkı sağladığı tespit edilmiştir (Aydın \& Tavukçu, 2019).

Bankaların mevcut müşterileriyle çalışmaya devam edip etmediğini gösteren müşteri tahmin sonuçları bankaların müşteri kaybına uğrayıp uğramadığ 1 konusunda da bilgi vermektedir. Aktif çalışılan müşteri sayısındaki sürekli azalma banka açısından müşteri kayıplarına neden olabilecektir.

Müşteri kayıplarının yarattığı bir takım olumsuz sonuçlar söz konusudur. Müşteri kayıpları işletmenin karlılığını ve pazar payını olumsuz etkilemekte (Colgate \& Hedge, 2001; Frederick \& Sasser, 1990; Keaveney, 1995) müşteriler için yapılan ve boşa giden iç yatırım maliyetlerine (Colgate, Stewart \& Kinsella, 1996) ve işletmenin yeni müşteri kazanımı sağlamak için üstlendiği maliyetlere de (Fornell \& Wernerfelt, 1987) neden olabilmektedir.

Müşteri kaybını tahmin etmeye yönelik literatür incelemesi yapıldığında ise müşteri kaybının tahmin edilmesi amacıyla çalışmaların bir kısmının makine öğrenmesi yöntemleri üzerine yoğunlaştıkları tespit edilmiştir. Bu yöntemlerin arasında Destek Vektör Makinaları (Farquad, Ravi \& Raju, 2014; Gordini \& Veglio, 2017; Moeyersoms \& Martens, 2015) Yapay Sinir Ağları (Tsai \& Lu, 2009; Xie \& Li, 2008; Zhao, Li, Li, Liu \& Ren, 2005) yer almaktadir.

Bankacılık işlemleri üzerine öğrenen makine yöntemleri kullanılarak yapılan literatür çalışmalarını incelediğimizde ise bu alanda sınırlı sayıda çalışmanın olduğu görülmektedir.

Pacelli ve Azzollini (2011), çalışmalarında kredi risk yönetimi tahminine yönelik yapay sinir ağları yöntemi ile incelenmiştir (Pacelli \& Azzollini, 2011).

Nazari ve Alidadi (2013), İran bankalarındaki iyi müşteriler ile kötü müşterileri sınıflandırma kriterlerini belirlemeyi amaçlamıştır. Çalışmada yapay sinir ağları kullanılarak banka müşterilerinin kredi risk oranı ölçülmüştür (Nazari \& Alidadi, 2013). 
Altunöz (2013), bankaların başarısızlıklarını yapay sinir ağları modeli ile test etmiştir. Çalışma sonucunda yapay sinir ağları bu alandaki yüksek öngörü başarısıyla ön plana çıkmıştır (Altunöz, 2013).

Sayıcı (2018) bankalarda ihtiyaç kredilerinin skorlamasını yapay sinir ağları yöntemini kullanılarak incelemiştir. Sonuçlar, ihtiyaç kredilerinin ülkemizde hızla yaygınlaştığını ve bireysel krediler içerisinde ise payının arttığını göstermiştir (Sayıcı, 2018).

Balcığlu ve Sezen (2019), yapay sinir ağları yöntemini kullanarak banka müşterilerinin, bankadan ayrılma olasılığının tahmin etmişlerdir. Çalışmalarının sonucu olarak, daha küçük bir grubu ayrılma potansiyeli olan müşteri olarak belirlemişlerdir (Balcioglu \& Sezen, 2019).

Literatürde hizmet kalitesi ile müşteri memnuniyeti arasındaki ilişkiyi araştıran çalışmalarda kullanılan analiz yöntemlerinden en sık rastlanan ölçüm yönteminin çoklu doğrusal regresyon analizinin olduğu çalışmalardır (Anton, 1996; Landrigan, 1999). Ancak yapay sinir ağları yöntemi, çoklu doğrusal regresyon analizine bir alternatif olarak da kullanılmaya başlanmış ve daha iyi sonuçlar verdiği gözlemlenmiştir (Uysal \& Roubi, 1999; Nguyen \& Cripps, 2001). Sonuç olarak literatürde yapılan çalışmalarda müşteri memnuniyetini değerlendirmeye yönelik kullanılan farklı yöntemlerin yanı sıra bankacılık işlemlerinde kredi skorlama, kredi riski tahmininde ve banka finansal başarısızlıklarını tahmin etmeye yönelik öğrenen makine yöntemlerinin kullanıldığı çalışmaların olduğu ancak mevduat bankalarına ait müşteri tahminine yönelik öğrenen makine yöntemlerini kullanan çalışmaların ise yetersiz olduğu dikkat çekicidir. $\mathrm{Bu}$ araştırma ile mevduat bankalarının müşteri tahminin yapay sinir ağları ve destek vektör regresyonu analizleriyle değerlendirilerek diğer yöntemlerden farklı olarak nasıl başarılı bir performans gösterdiği tespit edilecektir.

\section{Araştırma Yöntemi ve Veriler}

\subsection{Veri Seti}

Çalışmada, Bankacılık Düzenleme ve Denetleme Kurumu tarafından paylaşılan Haziran 2010 ve Ekim 2020 arasındaki aylık dönemleri kapsayan 2500 adet veri kullanılmıştır. Türkiye'deki faaliyet gösteren ve Bankacılık Düzenleme ve Denetleme Kurumu tarafından kategorize edilen mevduat bankaları araştırmaya konu edilmiştir. $\mathrm{Bu}$ kategoriler; kamu mevduat bankaları, yerli özel mevduat bankaları ve yabancı özel mevduat bankalarıdır. Çalışmanın modeli kurulurken değişkenler için bankacılık sektörünün iç dinamikleri alınması karar verilmiştir. $\mathrm{Bu}$ nedenle, modelin giriş birimleri araştırmaya konulan bankaların personel sayısı, şube sayısı, bilançolarındaki toplam mevduatları ve kredileridir. Bankaların iç dinamiklerinin giriş birimi olarak seçilmesinin nedeni literatür kısmında da belirtildiği gibi bankaların kendi müşteri politikalarının performansını müşteri tahmininde önemli bir etken olarak düşünülmesidir. Bu bakımdan bir bankanın en büyük iki faaliyet konusu olan mevduat toplamak ve kredi vermek unsurları ve bu faaliyeti 
gerçekleştirecek olan şube ve personel sayıları giriş birimi olarak seçilmiştir. Çıkış birimi olarak bu bankaların mudi sayısı belirlenmiştir. Öğrenen makine yöntemlerinin uygulaması ve analizleri için Knime programı tercih edilmiştir.

Çalışmada öğrenen makine öğrenmesi yöntemlerinin performansının iyileştirmek ve doğruluk oranını arttırmak için normalizasyon yöntemi kullanılmıştır. Normalizasyon yöntemi olarak min-max, z-score, medyan ve sigmoid aktivasyon fonksiyonu gibi yöntemler bulunmaktadır. Bu çalışmada min-max normalleştirme yöntemi kullanılarak orijinal veriler 0-1 aralığında doğrusal dönüşüm ile normalizasyon işlemi gerçekleştirilmiştir. Denklem 1 'de min-max normalleştirme formülü verilmiştir.

$$
x^{\prime}=\frac{x_{i}-x_{\min }}{x_{\max }-x_{\min }}
$$

x' normalize edilmiş veriyi, xi girdi değerini, $x_{\min }$ girdi seti içerisinde yer alan en küçük sayıyı, $x_{\max }$ girdi seti içerisinde yer alan en büyük sayıyı göstermektedir.

\subsection{Tahmin Yöntemleri}

\subsubsection{Yapay Sinir Ağları}

Yapay sinir ağları (YSA), insan beyninin nöro-fizyolojik yapısını matematiksel olarak modelleyerek işlemlerini taklit etmek için geliştirilmiş bilgisayar sistemleridir (Zhang, 2001). YSA "öğrenme" yeteneğine sahiptir; yani, performansını iyileştirmek için denetimli veya denetimsiz öğrenme yoluyla eğitilebilmektedir (Chang \& Chao, 2006). Yapay sinir ağları, mimarilerine (katman sayısı), topolojilerine (bağlantı modeli, ileri besleme veya tekrarlayan vb.) ve öğrenme çeşidine göre kategorize edilmektedir. Uygulamaların çoğu, ileri beslemeli ağ yapısını ve hata geri yayılımı öğrenimini kullanmaktadır.

İleri beslemeli ağ genellikle giriş, gizli ve çıkış katmanları olarak tanımlanan üç katmandan oluşan hiyerarşik bir yapıdan oluşmaktadır. Giriş katmanındaki her düğüm, ağırlıklı bağlantılar kullanılarak gizli katmandaki tüm düğümlere bağlanır. Ağ bağlantıları üzerindeki ağırlıklar, veri uydurma modelinin parametrelerini belirlemektedir. Giriş katmanındaki düğüm sayısı modellenecek sistemdeki girdi sayısına eşittir. Gizli katmanlardaki düğüm sayıları ve büyüklükleri istenen tahmin doğruluğu ve YSA modelinin performansı gibi konulara göre belirlenen ayarlanabilen parametrelerdir (Patel et al., 2007). Çıkış katmanı ise giriş değerlerine ve seçilen parametrelere göre hesaplanmış bilgi üretmektedir. Veriler ağa giriş katmanı üzerinden girmekte, gizli katmandan geçerek ilerlemekte ve çıktı katmanından çıkmaktadır. Her gizli katman ve çıktı katmanı düğümü, üstündeki düğümlerden (giriş katmanı veya gizli katman) veri toplar ve bir etkinleştirme işlevi uygular. Etkinleştirme işlevleri birkaç şekilde olabilir. Aktivasyon fonksiyonunun türü, ağ içindeki nöronun durumu ile belirtilir. Çoğu durumda, giriş katmanı nöronlarının bir aktivasyon işlevi yoktur, çünkü onların rolü girdileri gizli katmana aktarmaktır (Khashei, Hamadani \& Bijari, 2012). Şekil 1'de Yapay sinir ağı modeli görülmektedir. 
Şekil: 1

YSA Modeli

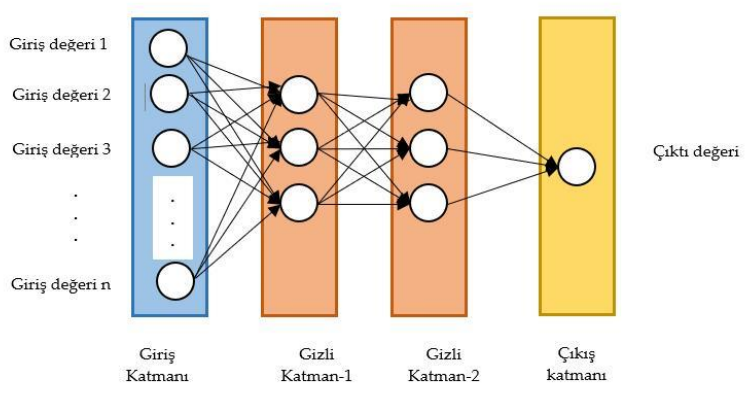

Geri yayılım öğrenme algoritması ileri besleme ve geri yayılma ağılık eğitimi olmak üzere iki prosedürden oluşmaktadır. Girdi verisi seti, çıktının bir tahminini vermek için ağ üzerinden yayılır. Tahmindeki hata bilgisine göre ağırlıklar sistematik olarak güncellemek için kullanılır (Hancke \& Malan, 1998). Ağ, eğitim verisi çıktıları ile ağın tahmin edilen çıktıları arasındaki hata yeterince küçük olana kadar ağırlıkları değiştirerek eğitilmektedir (Mesroghli, Jorjani \& Chelgani, 2009).

Bir yapay sinir ağı modelinde giriş hücrelerindeki bilgiler ara katman hücrelerine aktarılırken ilgili ağırlıklar ile çarpılmakta ve ağırlıklı toplam fonksiyonuna göre her ara katman hücresinin NET girdisi hesaplanmaktadır:

$$
N E T_{p}=\sum_{i} w_{i p} x_{i}
$$

Burada $\mathrm{NET}_{\mathrm{p}}$ ara katmanın p. hücresine olan girdi; $w_{\text {ip }}$ giriş katmanının i. hücresini, ara katmanın $p$. hücresine bağlayan ağırlık; $x_{i}$ giriş katmanındaki i. hücresinin çıkışını temsil etmektedir. Bulunan NET girdi, bir aktivasyon fonksiyonundan geçirilerek, ara katman hücrelerinin çıkışı bulunmaktadır.

$$
F_{p}=f\left(N E T_{p}\right)
$$

Burada $F_{p}$ ara katmanın p. hücresinin aktivasyon fonksiyonunu göstermektedir. Kullanılacak aktivasyon fonksiyonun türevlenebilir olması şarttır.

$\mathrm{Bu}$ aşamadan sonra hedef değer ile çıkış hücresinde bulunan değeri kullanarak hata hesaplaması yapılmaktadır. Hata hesaplaması:

$$
\varepsilon_{p}=\left(T_{p}\right)-\left(F_{p}\right)
$$

$\varepsilon_{\mathrm{p}}$ yapılan hata; $\mathrm{T}_{\mathrm{p}}$ hedeflenen çıkış değeri; $\mathrm{F}_{\mathrm{p}} \mathrm{p}$. Hücrenin hesaplanan değerini göstermektedir. 


\subsubsection{Destek Vektör Regresyonunu}

Destek vektör regresyonu (SVR), Vapnik tarafindan önerilen evrensel bir öğrenme algoritmasıdır (Cortes \& Vapnik, 1995; Vapnik, 2013). SVR, az miktarda örnekle öğrenme problemlerini çözmeyi sağlayan istatistiksel bir öğrenme teorisine dayanmaktadır (Tan, Zhang, Xia, Fang \& Chen, 2015). Ek olarak, SVR'nin doğrusal olmayan sorunları ele alma konusunda güçlü bir yeteneği vardır ve çok çeşitli alanlarda başarıyla kullanılmaktadır (Azamathulla, Ghani, Chang, Hasan \& Zakaria, 2010; Lu, Lee \& Chiu, 2009; Rao \& Gopalakrishna, 2009).

Destek vektör regresyonu, Vapnik'in $\varepsilon$-duyarsiz kayıp fonksiyonunun ortaya çıkmasıyla doğrusal olan ve olmayan sistemleri tahmin etmek ve çözmek için güçlü bir yaklaşım olarak kullanılmaya başlanmıştır (Lijuan \& Guohua, 2016).

Doğrusal olmayan destek vektör regresyonu Şekil 2'de gösterilmiştir.

Şekil: 2

\section{Doğrusal Olmayan Destek Vektör Regresyonu}

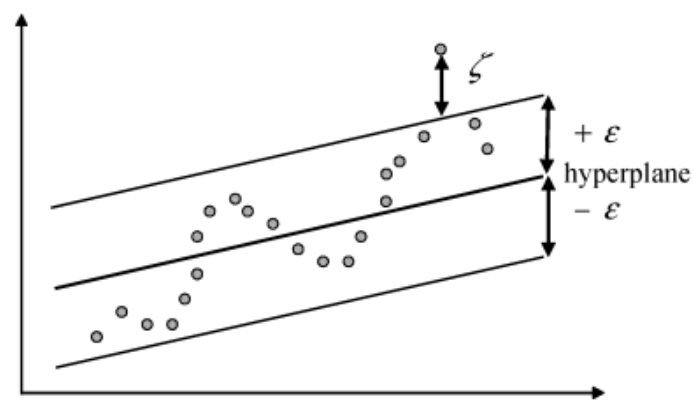

Kaynak: Wu, Ho \& Lee, 2004.

$\ell$ 'nin toplam eğitim örneklerinin sayısını gösterdiği Denklem 5'teki gibi bir veri seti olduğunu düşüldüğünde:

$$
D=\left\{\left(x^{1}, y^{1}\right), \ldots,\left(x^{\ell}, y^{\ell}\right)\right\}, x \in R^{n}, y \in R
$$

Destek vektör regresyonu için doğrusal fonksiyon:

$$
f(x)=w \cdot \phi((x)+b
$$

Burada $\mathrm{w}$ ve b sırasıyla ağırlık vektörü ve bias'tır. $\phi(x)$ çekirdek fonksiyonu göstermektedir. 
Amacımız $\omega$ ve b'nin değerini bulmak ve böylece $x$ değerlerinin regresyon riskini en aza indirgeyerek belirlemektir. Regresyon riskini indirgeyerek tahmin etmede hata oranı minimize edilecektir. Böylece daha yüksek doğruluk oranı ile tahmin başarısı sağlanacak; modelin güvenilirliği ve performansı artması sağlanacaktır. Regresyon riskinin minimize edilmesiyle şu şekilde çözülebilir:

$$
R_{\text {reg }}(f)=C \sum_{i=0}^{\ell} \Gamma\left(f\left(\chi_{i}\right)-y_{i}\right)+\frac{1}{2}\|w\|^{2}
$$

Burada $\Gamma$ (.) bir maliyet (cost) fonksiyonudur, C sabittir (constant) ve $\omega$ vektörü veri noktaları cinsinden şöyle yazılabilir:

$$
w=\sum_{i=1}^{\ell}\left(\alpha_{i}-\alpha_{i}^{*}\right) \Phi\left(x_{i}\right)
$$

Burada $\alpha$ Lagrange çarpanlarını göstermektedir. Optimizasyon yaparken, Lagrange çarpanı metodu bir fonksiyonun maksimum ve minimum noktalarını bulmak için kullanılan bir yöntemdir. $\ell$ toplam eğitim örneklerinin sayısını, $\phi(x)$ çekirdek fonksiyonu göstermektedir.

Bir SVR için, uygun bir çekirdek seçmek, öğrenme sürecinin başarısı için zorunludur. Bir SVR'nin karmaşıklığı ile ayrılamayan noktaların sayısı arasındaki ödünleşimi kontrol eden düzenlileştirme parametresi de önemlidir. SVR çekirdekleri arasında doğrusal çekirdek, polinom çekirdeği, dizin çekirdeği, çift sinir aği çekirdeği ve radyal temel işlevi (RBF) çekirdekleri bulunmaktadır. Bu çekirdeklerde, RBF çekirdeği en popüler çekirdek işlevidir ve genel olarak daha iyi kararlılığa sahiptir (Hsu \& Lin, 2002).

Radyal temel işlev (RBF) çekirdeği:

$$
K\left(x_{i}, x_{j}\right)=\exp \left(-\gamma \mid\left(\left.x_{i} \cdot x_{j}\right|^{2}\right)\right.
$$

Burada <x, y> iç çarpımı göstermektedir. Aşırı tahmin söz konusu olduğunda, üstel ifade yaklaşık olarak doğrusallaşır ve yüksek boyutlu doğrusal olmayan yapısını kaybetmeye başlar. Öte yandan, eğer gerçek değerden daha düşük tahmin gerçekleşiyorsa, fonksiyon düzgünleştirmeyecek ve karar sınırı ise eğitim verisindeki gürültü değerlere karşı son derece duyarlı olacaktır (Güldoğan, 2017).

Burada, bir regresyon fonksiyonu bulunmaya çalışılmaktadır. Bu fonksiyon " $\epsilon$ duyarsı" kayıp fonksiyonu kullanılarak elde edilmektedir. $\varepsilon$-duyarsız kayıp fonksiyon en yaygın kullanılan maliyet fonksiyonudur. Fonksiyon:

$$
\Gamma\left(f\left(\chi_{i}\right)-\gamma\right)=\left\{\begin{array}{c}
|f(x)-\gamma|-\varepsilon, \text { for }|f(x)-\gamma| \geq \varepsilon \\
0, \text { diğer }
\end{array}\right.
$$

İkinci dereceden optimizasyon problemini çözerek regresyon riski ve e-duyarsız kayıp fonksiyonu en aza indirilebilmektedir. Optimizasyon nesnesi için: 


$$
\min : \frac{1}{2} \sum_{i, j=1}^{\ell}\left(\alpha_{i}^{*}-\alpha_{i}\right)\left(\alpha_{j}^{*}-\alpha_{j}\right) k\left(x_{i}, x_{j}\right)-\sum_{i=1}^{\ell} \alpha_{i}^{*}\left(y_{i}-\varepsilon\right)-\alpha_{i}\left(y_{i}+\varepsilon\right)
$$

Lagrange çarpanları $\alpha_{\mathrm{i}}$ ve $\alpha_{\mathrm{i}}{ }^{*}$, tahminleri hedef değer olan $\mathrm{y}_{\mathrm{i}}^{\prime}$ ye doğru iten kuvvetler olarak hareket eden yukarıdaki ikinci dereceden problemin çözümlerini temsil etmektedir. Lagrange çarpanlarının sadece sıfır olmayan değerleri regresyon hattını tahmin etmede yararlıdır ve destek vektörleri olarak bilinmektedir. C sabiti, tahmin hatalarına verilen cezaları belirlemektedir. w'nin değeri Lagrange çarpanlarına göre çözülmektedir. b değişkeni için, Lagrange çarpanlarının ve kısıtlamalarının ürününün 0'a eşit olması gerektiği anlamına gelen Karush-Kuhn-Tucker (KKT) koşulları uygulanarak hesaplanabilir.

$$
\begin{aligned}
& \alpha_{i}\left(\varepsilon+\xi_{i}-y_{i}+\left(w, x_{i}\right)+b\right)=0 \\
& \alpha_{i}^{*}\left(\varepsilon+\xi_{i}^{*}+y_{i}-\left(w, x_{i}\right)-b\right)=0 \\
& \left(C-\alpha_{i}\right) \xi_{i}=0 \\
& \left(C-\alpha_{i}^{*}\right) \xi_{i}^{*}=0
\end{aligned}
$$

$\xi_{\mathrm{i}}$ ve $\xi_{\mathrm{i}}^{*}, \varepsilon$ tüpü dışındaki hataları ölçmek için kullanılan değişkenlerdir. $\alpha_{\mathrm{i}}^{\alpha} \varepsilon(0, \mathrm{C})$ için $\alpha_{\mathrm{i}}, \alpha_{\mathrm{i}}^{*}=0$ ve $\xi_{\mathrm{i}}^{*}=0$ olduğunda $\mathrm{b}$ hesaplaması şu şekilde yapılmaktadır:

$$
\begin{aligned}
& b=y_{i}-\left(w, x_{i}\right)-\varepsilon \text { for } \alpha_{i} \in(0, C) \\
& b=y_{i}-\left(w, x_{i}\right)+\varepsilon \text { for } \alpha_{i}^{*} \in(0, C)
\end{aligned}
$$

Buralarda çekirdek fonksiyonları olan düzenleme parametresi $C$ ve çağ değeri $\varepsilon$ değerlerini deneyerek ideal değeri bulmak gerekmektedir.

\subsection{Modellerin Değerlendirilmesi}

Yapay sinir ağları, destek vektör makineleri ve çoklu doğrusal regresyon modellerinin başarılarının karşıllaştırılmasında düzeltilmiş belirleme katsayısı (R2), ortalama mutlak hata (MAE), ortalama kare hata (MSE), hata kareler ortalamasının karekökü (RMSE) ve ortalama mutlak yüzde hata (MAPE) kriterleri kullanılmıştır.

$\mathrm{Bu}$ kriterlere ait denklemler aşağıda verilmiştir.

$$
\begin{aligned}
& R^{2}=1-\frac{\sum\left(y_{i}-y_{i}^{*}\right)^{2}}{\sum\left(y_{i}-y_{\text {ort }}\right)^{2}} \\
& M A E=\frac{\sum_{i=1}^{n}\left|y_{i}-y_{i}^{*}\right|}{n} \\
& M S E=\frac{1}{n} \sum_{i=1}^{n}\left(y_{i}-x_{i}\right)^{2} \\
& R M S E=\sqrt{\frac{1}{n} \sum_{i=1}^{n}\left(y_{i}-x_{i}\right)^{2}}
\end{aligned}
$$




$$
M A P E=\frac{\sum_{i=1}^{n}\left|\frac{y_{i}-y_{i}^{*}}{y_{i}}\right|}{n} \cdot 100
$$

Burada i veri sayısını, y gerçek değeri, yort ortalama gerçek değeri ve x tahmin değerini göstermektedir.

Modellerin değerlendirilmesinde kullanılan parametrelerin açıklamaları, değer aralıkları ve istenen değer bilgileri aşağıda verilmiştir (Veri bilimci, 2021):

Verilerin doğrusal bir eğriye ne kadar iyi uyduğunu gösteren R2 değerinin 1 olmas1, test verilerinin doğrusal bir eğri sağlandığını göstermektedir. Bağımsız değişkeninin toplam varyasyonun yüzde kaçı ile açıklanabildiğini göstermektedir. R2 değerinin istenen değerlere yani 1'e yaklaşması doğrusal bir eğri sağlamaya yakın olduğu görülmektedir.

RMSE, tahmin edilen değerler ile gerçek değerler arasındaki uzaklığın bulunmasında kullanılan ve hatanın büyüklüğünü gösteren bir büyüklüktür. Bir başka ifade ile RMSE tahmin hatalarının standart sapmasıdır. Hata, regresyon hattının veri noktalarından ne kadar uzakta olduğunun bir ölçüsüdür; RMSE ise bu kalıntıların ne kadar yayıldığının bir ölçüsüdür. RMSE değeri 0'dan $\infty$ 'a kadar değişebilir. RMSE değerinin sıfır olması modelin hiç hata yapmadığı anlamına gelmektedir. Bu yüzden RMSE değerinin sıfır değerine yakın olması istenmektedir.

MSE değeri bir regresyon eğrisinin bir dizi noktaya ne kadar yakın olduğunu göstermek için kullanılmaktadır. MSE, tahmin modelinin performansını ölçer, her zaman pozitif değerlidir. Sıfırı yakın tahmin modellerinin daha başarılı söylenebilir.

MAE iki sürekli değişken arasındaki farkı gösteren bir büyüklüktür. Bir başka deyişle gerçek değer ile veriye en iyi uyan çizgi arasındaki ortalama dikey mesafeyi göstermektedir. MAE, hataların ortalama büyüklüğünü ölçen doğrusal bir skordur. MAE 0'dan $\infty$ 'a kadar değişebilen değerler almaktadır. Negatif olan değerler yani daha MAE değerinin düşük olması tahmin modelinin başarılı olduğunu göstermektedir.

MAPE, regresyon modellerinin doğruluğunu ölçmekte kullanılan bir büyüklüktür. Gerçek değerler arasında sıfır içerenler varsa, sıfır ile bölünme olacağı için MAPE hesaplanamaz. Çok düşük tahmin değerleri için yüzde hatası \%100'ü geçemez, ancak çok yüksek tahmin değerleri olduğunda yüzde hatasının üst sınırı yoktur. MAPE değeri \%10'un altında olan modeller "çok iyi”, \% $10<\mathrm{MAPE}<\% 20$ arasında olan modelleri "iyi”, \% 20 $<$ MAPE < \% 50 arasında olan modelleri "kabul edilebilir" ve \%50< MAPE "nin üzerinde olan modeller ise "yanlış ve hatalı" olarak ifade edilmektedir.

\section{Ampirik Bulgular}

Çalışmada mevduat bankalarına ait toplam 2500 adet veri (bağımlı değişken olarak müşteri sayısı; bağımsız değişkenler ise banka şube sayısı, çalışan sayısı, toplam mevduat, toplam krediler) kullanılmıştır. Yapay zekâ tekniklerinin uygulaması ve analizleri için 
Knime programı tercih edilmiştir. Yapay sinir ağları modelinde verilerin \%70’i eğitim, \%30'u test amaçlı olmak üzere rastgele seçilerek tasarlanan ağa aktarılmaktadır. Yapay sinir ağları ile yapılan testler sonucunda elde edilen istatistiksel sonuçlar Tablo 1'de görülmektedir.

Tablo: 1

YSA Yönteminin İstatiksel Analiz Sonuçları

\begin{tabular}{|c|c|c|c|c|c|}
\hline Banka Türleri & R2 & MSE & RMSE & MAE & MAPE \\
\hline Kamu mevduat Bankaları & 0,990 & 0,01 & 0,010 & 0,007 & 0,020 \\
\hline Yerli Özel Mevduat Bankaları & 0,983 & 0 & 0,005 & 0,004 & 0,019 \\
\hline Yabancı Özel Mevduat Bankaları & 0,993 & 0 & 0,022 & 0,007 & 0,057 \\
\hline Tüm Mevduat Bankaları & 0,993 & 0 & 0,006 & 0,003 & 0,038 \\
\hline
\end{tabular}

Çalışmada oluşan hata eğrileri Şekil 3'te görülmektedir.

Şekil: 3

\section{Hata Eğri Grafikleri}

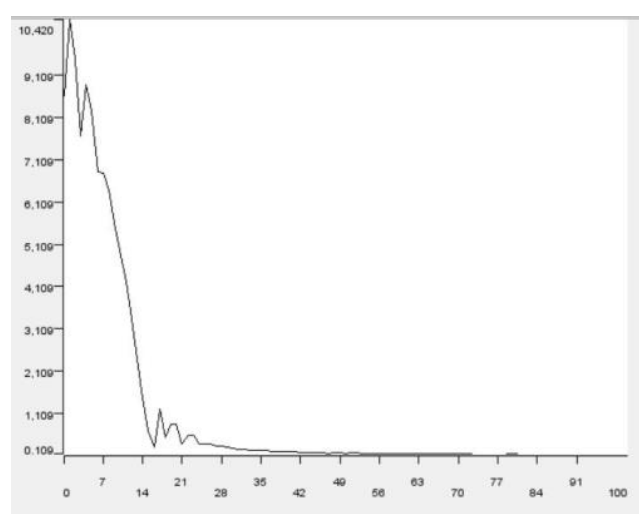

Kamu Mevduat
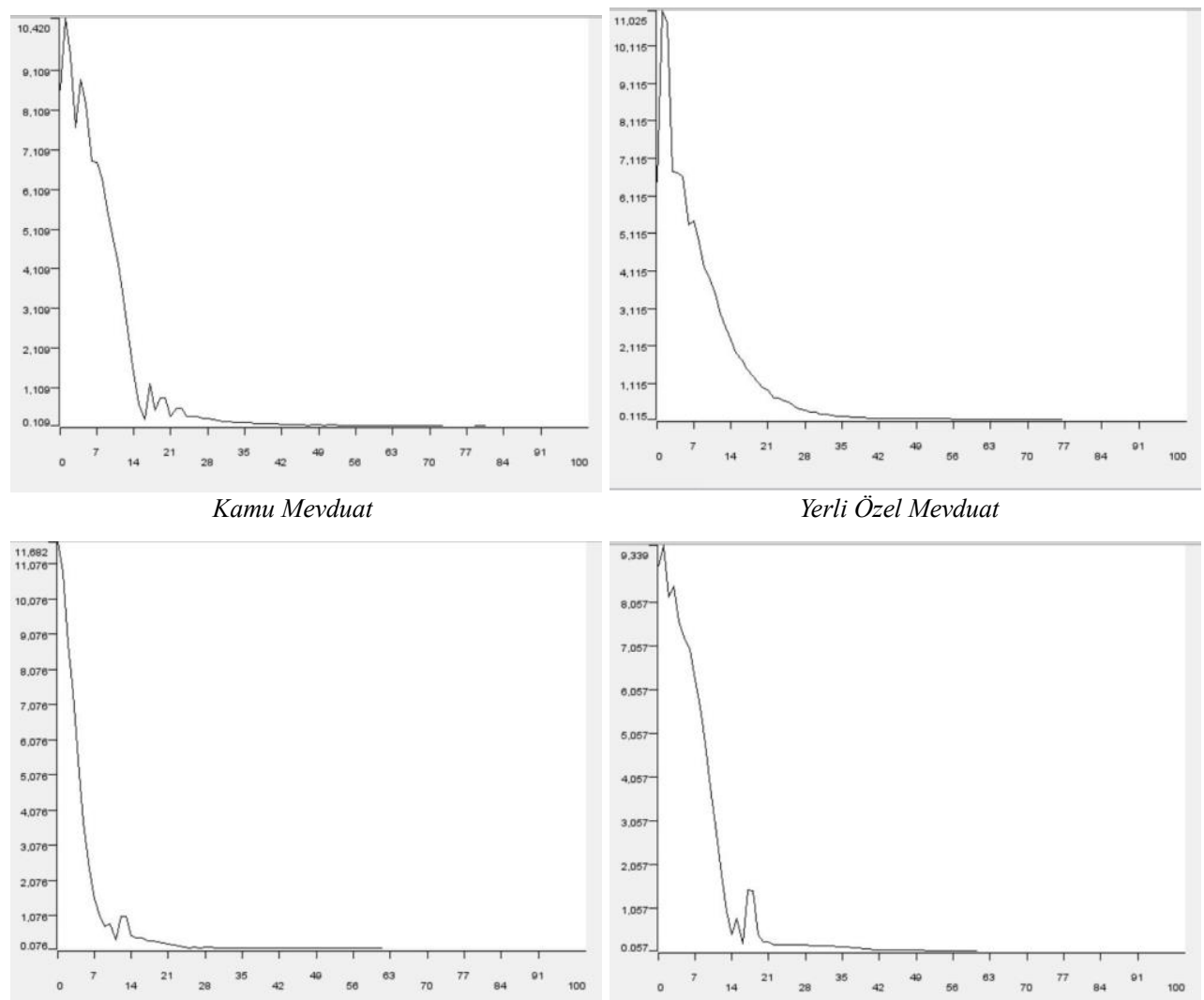

Yabancl Özel Mevduat

Yerli Özel Mevduat

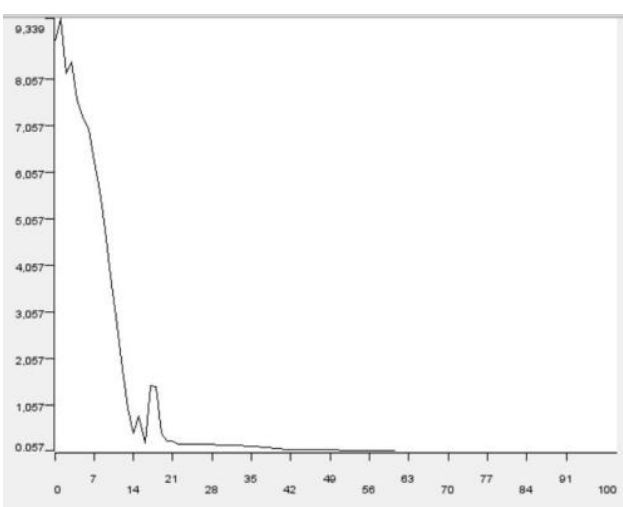

Toplam Mevduat 
Verilerin doğrusal bir eğriye ne kadar iyi uyduğunu gösteren R2 değerinin 1 olmas1, test verilerinin doğrusal bir eğri sağlandığını göstermektedir. Çalışmada MSE değerleri sıfır olduğu için ideal değerlerde olduğu görülmüştür. RMSE değeri sıfır ile sonsuz arasında değer alabilmektedir; değerinin sıfıra yakın olması istenmektedir. Çalışmada 0,005-0,022 aralığında olup istenen değere oldukça yakın olduğu görülmüştür. Çalışmada MAE 0,003 ile 0,007 aralığında; MAPE 0,019 ile 0,057 aralığında değerler almaktadır. MAE ve MAPE değerleri ideal modelde sıfır olması istenmektedir. Bu değerlerin sıfır veya sıfır yakın olması ideal kabul edilmektedir. Çalışma hem MAE hem de MAPE değeri için istenen değerlere çok yakındır.

Çalışmada SVR yöntemi olarak doğrusal olmayan regresyon yöntemi kullanılmıştır. SVR yönteminde çekirdek fonksiyonlardan polinom, hiperbolik fonksiyon ve çapsal tabanlı fonksiyon (Radial Basis Function- RBF) teknikleri kullanılarak testler yapılmış olup; başarılı sonucu verdiği için çekirdek fonksiyonu olarak çapsal tabanlı fonksiyon (RBF) tercih edilmiştir. Örtüşen ceza (Overlapping penalty), giriş verilerinin ayrılabilir olmaması durumunda kullanılan faydalı bir parametredir. Yanlış tahmin edilen her noktaya ne kadar ceza verileceğini belirlemekte böylelikle doğruluk oranının arttırılmasını sağlamaktadır. $\mathrm{Bu}$ çalışmada örtüşen ceza değerleri test edilmiş ve en iyi değeri 10' da verdiği görülmüştür.

Tablo 2'de Radial basis function (RBF) çekirdek fonksiyonu için SVR yöntemine göre performansları görülmektedir.

Tablo: 2

\section{Farklı SVR Modelleri İçin Test Sonuçları}

\begin{tabular}{|c|c|c|c|c|c|}
\hline Banka Türleri & $\mathrm{R} 2$ & MSE & RMSE & MAE & MAPE \\
\hline Kamu Mevduat Bankaları & 0,985 & 0,001 & 0,027 & 0,023 & 0,010 \\
\hline Yerli Özel Mevduat Bankaları & 0,989 & 0,001 & 0,034 & 0,027 & 0,020 \\
\hline Yabancı Özel Mevduat Bankaları & 0,900 & 0,001 & 0,028 & 0,019 & 0,010 \\
\hline Tüm Mevduat Bankaları & 0,906 & 0,001 & 0,024 & 0,018 & 0,204 \\
\hline
\end{tabular}

SVR yöntemine göre mevduat bankalarının müşteri tahmininde R2 değeri en düşük 0,900; en düşük 0,989 olmuştur. Çalışmada MSE değerleri 0,001 olduğu için ideal değerdedir. RMSE değerinin sıfıra yakın olması istenmekte; bu çalışmada 0,024-0,034 aralığında olup istenen değere çok yakın olduğu görülmektedir. MAE ve MAPE için ise en küçük değere sahip değerler ideal kabul edilmektedir. Çalışmada MAE 0,018 ile 0,027 aralığında; MAPE 0,010 ile 0,204 aralığında değerler almaktadır ve istenen değerlere çok yakın değerler olduğu görülmektedir.

Sonuçlara göre SVR yönteminin doğrusal bir eğri sağlanmaya çok yakın olduğu görülmektedir. Şekil 4'te SVR için serpilme diyagramı eğrisi görülmektedir. 


\section{Şekil: 4}

\section{SVR Serpilme Diyagramı Eğrisi}
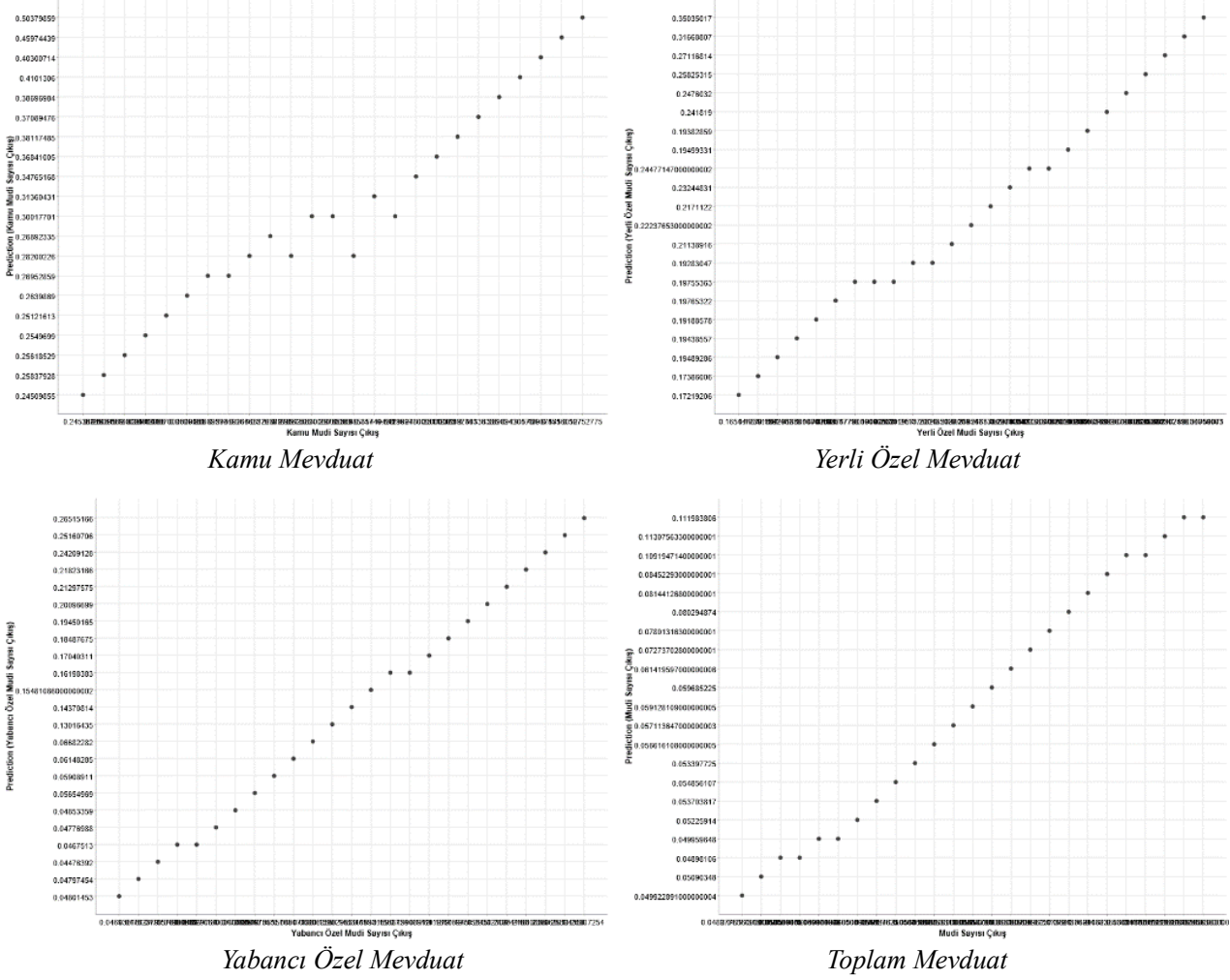

İki farklı analiz tekniğine göre yapılan testlerin ortalama istatistiksel sonuçlar Tablo 3'te gösterilmiştir.

Tablo: 3

İki Farklı Yapay Zekâ Tekniğine Göre Ortalama İstatiksel Sonuçlar

\begin{tabular}{|l|c|c|c|c|c|}
\hline Test Yöntemi & R2 & MSE & RMSE & MAE & MAPE \\
\hline Yapay Sinir Ağları & 0,989 & 0,002 & 0,010 & 0,005 & 0,033 \\
\hline Destek Vektör Regresyonu & 0,945 & 0,001 & 0,028 & 0,021 & 0,061 \\
\hline
\end{tabular}

Her iki yönteme göre istatistiksel ortalama değerler birbirine oldukça yakın ve başarılı değerler aldığı görülmektedir. Tablo 3 'teki test sonuçlarının grafiksel gösterimi Şekil 5'te görülmektedir. 
Şekil: 5

Ortalama Test Sonuçlarının Grafiksel Gösterimi

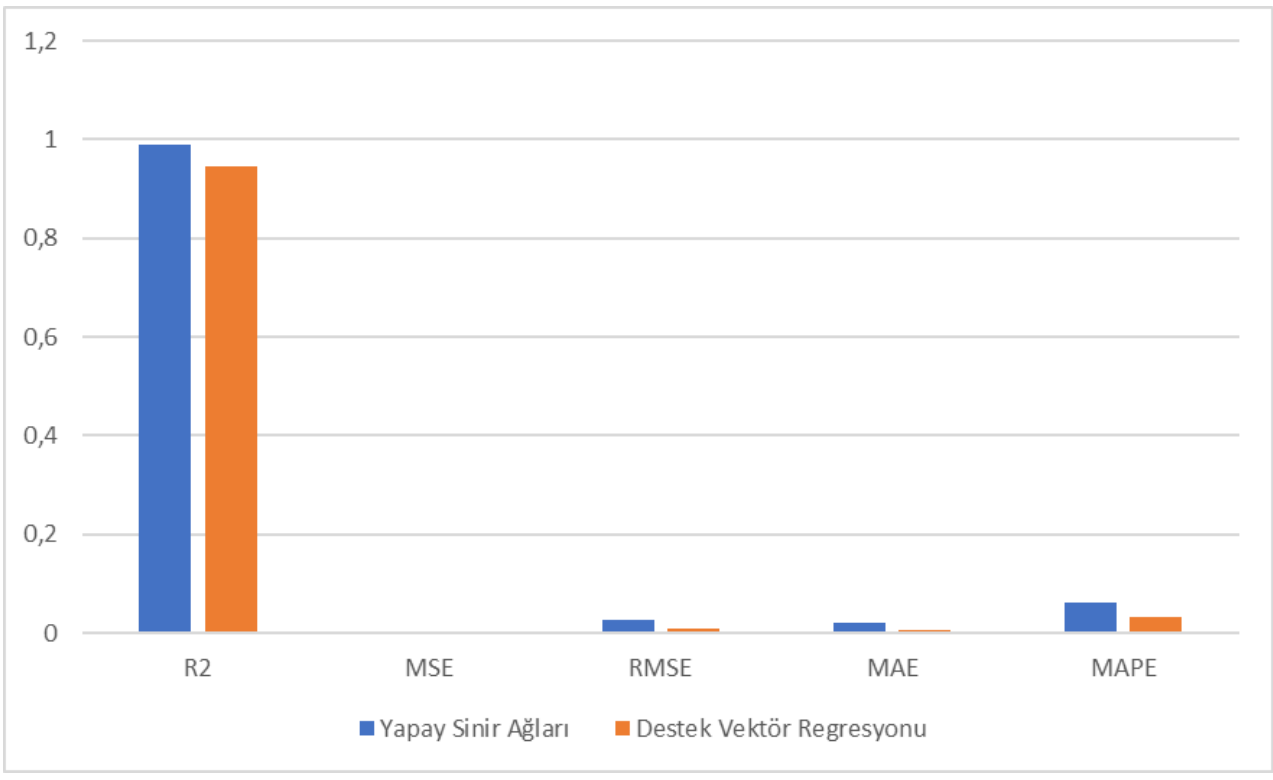

İki farklı makine öğrenmesi tekniğine göre yapılan analiz sonuçları karşılaştırıldığında iki makine öğrenmesi yönteminin de ideal değerlere yakın olmakla birlikte YSA yönteminin daha başarılı sonuçları olduğu görülmüştür.

\section{Sonuç ve Tartışma}

Küreselleşen finansal sistemin yoğun rekabeti içinde bankaların hem potansiyel müşterileri portföylerine kazandırmaları hem mevcut müşterilerini portföylerinde tutabilmeleri hem de mevcut müşterilerinde yeni finansal ürünlerle derinleşme sağlayabilmeleri her geçen gün biraz daha zorlaşmaktadır. Müşterilerin son y1llarda dijital kanallar aracılı̆̆ıyla bankacılıkta birçok bilgiye daha hızlı bir şekilde ulaşabilmesi, birçok bankanın sunduğu çeşitli ürünler arasında seçimler yapmaya çalışması sonucunda bankaların hizmetleriyle ilgili müşterilerin beklentileri her geçen gün artmaktadır. Bu amaçla bankalar rakip bankalardan daha iyi iş yapmak, müşteri isteklerini anlamak ve ihtiyaçlara hemen cevap vermek için çabalamaktadır.

Elde edilen analiz sonuçları, kamu, özel ve yabancı mevduat bankalarıyla çalışmalarını devam ettiren müşterilerin doğru tahmin edilmesinde bankalara ön bilgiler sunabileceği ve bu analiz sonuçları kapsamında bankaların müşteri kazanımı hedeflerini belirlemede banka üst yönetimi için yol gösterici olabileceğini göstermektedir. Müşteri tahmini raporları bankaların hizmet odaklı pazarlama stratejilerinden ziyade müssteri odaklı 
stratejiler ile hizmet sunmaları açısından önemlidir. Çünkü günümüzde bankalar müşteri ilişkileri yönetiminde müşteri memnuniyetini ön plana koymaktadır.

Çalışmada kullanılan yapay sinir ağları (YSA) ve destek vektör makineleri (DVM) yöntemleri müşteri sayılarının tahmininde oldukça başarılı sonuçlar vermiştir. En iyi uyumu veren modelin belirlenmesinde belirleme katsayıs1 (R2) ve hata varyansinı ifade eden kriterler (MSE, RMSE, MAE ve MAPE) dikkate alınmıştır Çalışmada elde edilen R2 değerleri yapay sinir ağları için 0,983 ile 0,993 arasında, destek vektör regresyonu kullanıldığında ise 0,900 ile 0,989 arasındadır. Bu değerler literatürdeki farklı konulardaki tahmin başarı değerleri ile karşılaştırıldığında oldukça yüksektir. Araştırma konusu olan çalışmalarda ulaşılan performans değerlerine göre yapay sinir ağları modelinin destek vektör regresyonu analizinden daha etkin bir performans sergilediği görülmektedir. Yapay sinir ağlarının destek vektör regresyonu analizine göre daha yüksek bir öngörüye sahip olduğu ve daha az hataya sahip sonuçlar verdiği görülmektedir.

Çalışmada oluşturulan model ve seçilen analiz teknikleri ile her banka kendi özelinde müşteri sayılarını başarılı bir şekilde tahmin edebilecektir. Bu bağlamda söz konusu bankalar yıl içinde veya belirli dönemler itibariyle kazandığı mevcut müşterileri ya da kaybettiği müşteri sayılarını ön görebilecek böylece karşılaştırma yapabilme olanaklarına sahip olacaklardır. Ayrıca tahmin sonuçları ile bankalar açısından müşteri sayılarındaki artış müşteri ihtiyaçlarına uygun ürün ve hizmetleri sunabildiklerini, müşteri sayısındaki azalma ise bankaların sürekli çalışmayı hedeflediği müşteriler için yeni ürünler geliştirmeleri gerektiği, ürün geliştirme aşamalarında müşteri ihtiyaçlarına öncelik vermeleri, bankaların geliştirecekleri yenilik stratejileri ve müşteri ilişkilerini geliştirme yönünde yeni politikaların oluşturması konusunda yol gösterici olacaktır.

Bir diğer önemli sonuç ise, bankacılık sektöründe kredibilitesi yüksek yeni müşterilerin kazanılması hem maliyetli hem de zaman alması bakımından zorlayıcıdır. Bu durum bankaların müşteri tatminini arttıracak ve onların bankalarına olan bağlılıklarını artırmaya yönelik yeni stratejiler geliştirmeleri yönünde hedefler oluşturmalarını sağlayacaktır. Türkiye'de faaliyet gösteren kamu, özel ve yabancı bankaların müşterilerinin başarılı bir şekilde tahmin edilmesi ile giderek artan müşterinin önemi ortaya konulmuştur. Yapılan tahmin sonuçları paralelinde bankaların mevcut müşterileri hakkında kısa sürede doğru bilgiye sahip olmaları rekabet ortamında bankalara pek çok avantaj sağlayabilecektir. Müşteri tahmin sonuçları ile bankalar mevcut müşterilerinin yeterliliği veya yetersizliği konusunda bilgi sahibi olabilecekler ve bu kapsamda yeni müşteri hedeflerini ihtiyaca yönelik olarak kolayca belirleyebileceklerdir. Ayrıca müşteri tahmin bilgileriyle müşteri sayılarını artırmaya yönelik planlama ve yenilikler kapsamında banka yönetiminin alacağı kararların hız kazanmasında etkili olabileceği öngörülmektedir. Bu doğrultuda bankalar müşteri sayılarını artırmak için müşteri memnuniyeti, müşteri ilişkilerinin sürekli iyileştirilmesi ve müşteri sadakatine yönelik stratejik politikalara ve hedeflere yönelmelidir. Bunu sağlayan bankalar sektörde rakiplerinden daha üstün bir şekilde faaliyetlerine devam edebilecektir. 
Yetiz, F. \& M. Terzioğlu \& M. Kayakuş (2021), "Makina Öğrenmesi Yöntemleri ile Türk Mevduat

Bankalarının Müşteri Tahminine Yönelik Bir Uygulama”, Sosyoekonomi, 29(50), 413-432.

\section{Kaynaklar}

Altuğ, N. \& Ş. Özhan (2018), Pazarlamada Güncel Gelişmeler, Nobel.

Altunöz, U. (2013), "Bankaların Finansal Başarısızlıklarının Yapay Sinir Ağları Modeli Çerçevesinde Tahmin Edilebilirliği”, DE Ü İ̈BF Dergisi, 28(2), 189-217.

Arasli, H. et al. (2005), "A comparison of service quality in the banking industry", International Journal of Bank Marketing, 23(7), 508-526.

Aydın, S. \& A. Tavukçu (2019), "İlişkisel pazarlama uygulamalarının müşteri sadakati, müşteri memnuniyeti ve müşterilerin tavsiye etme eğilimi üzerine etkisi: Türk katılım bankacılığ 1 sektöründe bir araştırma", Proceedings of the International Congress on Business and Marketing, İstanbul, Türkiye.

Azamathulla, H.M. et al. (2010), "Machine learning approach to predict sediment load-a case study", CLEAN-Soil, Air, Water, 38(10), 969-976.

Balcioglu, Y. \& B. Sezen (2019), "Yapay Sinir Ağları ile Banka Müşterilerinin Bankadan Ayrılma Olasılığının Tahmini”, Business and Organization Research, Izmir.

Başar, A. vd. (2015), "Banka Şubeleri İçin Uygun Yer Seçiminin Belirlenmesine Yönelik Tabu Arama Yaklaşımı: Bir Türk Bankası Uygulaması", Endüstri Mühendisliği Dergisi, 26(3), $2-22$.

Bilal-Zorić, A. (2016), "Predicting customer churn in banking industry using neural networks", Interdisciplinary Description of Complex Systems: INDECS, 14(2), 116-124.

Bülbül, S. (2019), “Türk bankacılık sektöründe müşteri memnuniyetinin katılım ve mevduat bankalarında karşılaştırmalı olarak değerlendirilmesi”, Yüksek Lisans Tezi, Gebze Teknik Üniversitesi, Gebze.

Chang, T.-C. \& R.-J. Chao (2006), "Application of back-propagation networks in debris flow prediction”, Engineering Geology, 85(3-4), 270-280.

Colgate, M. \& R. Hedge (2001), "An investigation into the switching process in retail banking services”, International Journal of Bank Marketing, 19(5), 201-212.

Colgate, M. et al. (1996), "Customer defection: a study of the student market in Ireland", International Journal of Bank Marketing, 14(3), 23-29.

Cortes, C. \& V. Vapnik (1995), "Support-vector networks", Machine Learning, 20(3), 273-297.

Demir, F.O. \& Y. Kırdar (2007), "Müşteri ilişkileri yönetimi: CRM. Review of Social”, Economic \& Business Studies, 8, 293-308.

Farquad, M.A.H. et al. (2014), "Churn prediction using comprehensible support vector machine: An analytical CRM application", Applied Soft Computing, 19, 31-40.

Fornell, C. \& B. Wernerfelt (1987), "Defensive marketing strategy by customer complaint management: a theoretical analysis", Journal of Marketing Research, 24(4), 337-346.

Frederick, F.R. \& W.E. Sasser (1990), “Zero defections: quality comes to services”, Harvard Business Review, 68(5), 105.

Gençtürk, M. vd. (2011), "Bireysel Bankacılıkta Müşteri Memnuniyetini Etkileyen Faktörler: Burdur ve Isparta İllerinde Bir Uygulama”, SDÜ İIBF Dergisi, 16(2), 59-77.

Gordini, N. \& V. Veglio (2017), "Customers churn prediction and marketing retention strategies. An application of support vector machines based on the AUC parameter-selection technique in B2B e-commerce industry", Industrial Marketing Management, 62, 100-107. 
Yetiz, F. \& M. Terzioğlu \& M. Kayakuş (2021), "Makina Öğrenmesi Yöntemleri ile Türk Mevduat Bankalarının Müşteri Tahminine Yönelik Bir Uygulama”, Sosyoekonomi, 29(50), 413-432.

Güldoğan, E. (2017), “Çeşitli çekirdek fonksiyonlari ile oluşturulan destek vektör makinesi modellerinin performanslarinin incelenmesi: Bir klinik uygulama”, İnönü Üniversitesi ve Mersin Üniversitesi Biyoistatistik ve Tıp Bilişimi Anabilim Dalı, Doktora Tezi.

Gürbüz, F. (2016), "Bankacılık Sektöründe Müşteri Değerlendirme Kriterleri Seçiminde Örnek Bir Karar Verme Süreci”, Nevşehir Bilim ve Teknoloji Dergisi, 5(2), 167-184.

Hancke, G.P. \& R. Malan (1998), "A modal analysis technique for the on-line particle size measurement of pneumatically conveyed pulverized coal", IEEE Transactions on Instrumentation and Measurement, 47(1), 114-122.

Hsu, C.-W. \& C.-J. Lin (2002), “A comparison of methods for multiclass support vector machines”, IEEE transactions on Neural Networks, 13(2), 415-425.

Johnston, R. (1997), "Identifying the critical determinants of service quality in retail banking: importance and effect", International Journal of Bank Marketing, 15(4), 111-116.

Keaveney, S.M. (1995), "Customer switching behavior in service industries: An exploratory study", Journal of Marketing, 59(2), 71-82.

Khashei, M. et al. (2012), “A novel hybrid classification model of artificial neural networks and multiple linear regression models", Expert Systems with Applications, 39(3), 2606-2620.

Lijuan, W. \& C. Guohua (2016), "Seasonal SVR with FOA algorithm for single-step and multi-step ahead forecasting in monthly inbound tourist flow", Knowledge-Based Systems, 110, 157-166.

Lu, C.-J. et al. (2009), "Financial time series forecasting using independent component analysis and support vector regression", Decision Support Systems, 47(2), 115-125.

Mesroghli, S. et al. (2009), "Estimation of gross calorific value based on coal analysis using regression and artificial neural networks", International Journal of Coal Geology, 79(12), 49-54.

Moeyersoms, J. \& D. Martens (2015), "Including high-cardinality attributes in predictive models: A case study in churn prediction in the energy sector", Decision Support Systems, 72, 7281 .

Nazari, M. \& M. Alidadi (2013), "Measuring credit risk of bank customers using artificial neural network", Journal of Management Research, 5(2), 17.

Özdemir, İ. (2012), "Bankacılıkta halkla ilişkiler ve müşteri ilişkileri”, Bankacılık ve Sigortacılık Araştırmaları Dergisi, 1(3), 4-15.

Pacelli, V. \& M. Azzollini (2011), “An artificial neural network approach for credit risk management", Journal of Intelligent Learning Systems and Applications, 3(02), 103.

Patel, S.U. et al. (2007), "Estimation of gross calorific value of coals using artificial neural networks", Fuel, 86(3), 334-344.

Rao, B.V. \& S. Gopalakrishna (2009), "Hardgrove grindability index prediction using support vector regression”, International Journal of Mineral Processing, 91(1-2), 55-59.

Sayı1, S.C. (2018), “İhtiyaç kredilerinde yapay sinir ağları uygulaması”, Doktora Tezi, Kadir Has Üniversitesi, İstanbul.

Sönmez, F. vd. (2015), "Mevduat bankalarının karlılığının yapay sinir ağları ile tahmini: Bir yazılım modeli tasarımı", BDDK Bankacıllk ve Finansal Piyasalar Dergisi, 9(1), 9-46.

Tan, P. et al. (2015), "Estimation of higher heating value of coal based on proximate analysis using support vector regression”, Fuel Processing Technology, 138, 298-304. 
TBB (2021), Bankacılık Sisteminde Banka, Çalışan ve Şube Sayıları Mart 2021, <https://www.tbb.org.tr/Content/Upload/istatistikiraporlar/ekler/1575/Banka_Calisan_ve _Sube_Sayilari-Mart_2021.pdf>, 20.04.2021.

Tsai, C.-F. \& Y.-H. Lu (2009), “Customer churn prediction by hybrid neural networks", Expert Systems with Applications, 36(10), 12547-12553.

Vapnik, V. (2013), “The nature of statistical learning theory”, Springer Science \& Business Media.

Veri Bilimci (2021), Makine Öğrenmesi MSE, RMSE, MAE, MAPE ve Diğer Metrikler, $<$ https://veribilimcisi.com/2017/07/14/mse-rmse-mae-mape-metrikleri-nedir>, 11.07.2021

Wu, C.-H. et al. (2004), "Travel-time prediction with support vector regression", IEEE Transactions on Intelligent Transportation Systems, 5(4), 276-281.

Xie, Y. \& X Li (2008), “Churn prediction with linear discriminant boosting algorithm”, 2008 International Conference on Machine Learning and Cybernetics.

Yazıcı, M. (2007), "Bankalarda kobi kredilerini değerlendirmeye ilişkin bir yaklaşım: Yapay sinir ağları”, Doktora Tezi, Kadir Has Üniversitesi İstanbul.

Zhang, G.P. (2001), "An investigation of neural networks for linear time-series forecasting”, Computers \& Operations Research, 28(12), 1183-1202.

Zhao, Y. et al. (2005), "Customer churn prediction using improved one-class support vector machine", International Conference on Advanced Data Mining and Applications. 